\title{
BAUDELAIRE, Le Spleen de Paris
}

\section{Ida Merello}

\section{OpenEdition \\ Journals}

\section{Edizione digitale}

URL: http://journals.openedition.org/studifrancesi/15706

DOI: 10.4000/studifrancesi. 15706

ISSN: 2421-5856

\section{Editore}

Rosenberg \& Sellier

\section{Edizione cartacea}

Data di pubblicazione: 1 décembre 2018

Paginazione: 522

ISSN: 0039-2944

\section{Notizia bibliografica digitale}

Ida Merello, «Baudelaire, Le Spleen de Paris», Studi Francesi [Online], 186 (LXII | III) | 2018, online dal 01 janvier 2019, consultato il 06 janvier 2021. URL: http://journals.openedition.org/studifrancesi/15706 ; DOI: https://doi.org/10.4000/studifrancesi.15706

Questo documento è stato generato automaticamente il 6 janvier 2021.

\section{(c)}

Studi Francesi è distribuita con Licenza Creative Commons Attribuzione - Non commerciale - Non opere derivate 4.0 Internazionale. 


\section{BAUDELAIRE, Le Spleen de Paris}

Ida Merello 


\section{NOTIZIA}

BAUDELAIRE, Le Spleen de Paris, présentation, notes, dossier, chronologie, bibliographie par Aurélia Cervoni et Andrea Schellino, Paris, Garnier-Flammarion, 2017, 307 pp.

Quest'edizione dei poèmes en prose di Baudelaire appare minuziosamente rigorosa sia nella lezione testuale che nell'apparato critico. In mancanza di una table des matières da parte dell'autore, i due curatori si basano sulla lista manoscritta presente alla biblioteca Jacques-Doucet; mentre per la restituzione dei testi scartano l'edizione del 1869 curata da Asselineau e Banville (le cui varianti rispetto ai testi usciti su rivista sarebbero potute dipendere dalla loro volontà), per recuperare invece proprio le pubblicazioni su rivista, con l'aggiunta dei manoscritti finiti in mano privata - forse inizialmente in deposito presso la Revue nationale et étrangère - con le correzioni di pugno dell'autore dei testi a stampa.

2 Nella presentazione, A. SCHELLINO e A. CERVONI ripercorrono la gestazione dell'opera, con i numerosi titoli concepiti, e la disseminazione di poèmes en prose su giornali e riviste. A loro volta, dopo gli studi di settore, e l'importante lavoro di Patrick LABARTHE (Gallimard, Foliothèque 2000) ripropongono una definizione di poème en prose, di impronta prettamente storica, basata sui tentativi di formulazione del genere a partire da Charles Sorel e Fontenelle. I testi sono fittamente annotati, con un grande lavoro di accostamento ai riferimenti che Baudelaire poteva aver avuto sotto mano, dai classici latini alla tradizione francese fino ai contemporanei, sono seguiti da un commento essenziale e accompagnati da un ampio dossier. Diviso in sezioni tematiche, il dossier accoglie documenti di corrispondenza e di prima ricezione dei testi, proponendo da ultimo accostamenti sia coi moralisti del Gran Secolo, di cui è nota la lettura precoce da parte di Baudelaire, sia con Vauvenargues, fino ai più diretti ascendenti di Poe e Aloysius Bertrand, e la chicca di un riferimento al romanticismo nero di Pétrus Borel. A seguire, una cronologia e una bibliografia di selezione accurata. 